\title{
Study of Histopathological Patterns in Breast Lumps
}

\author{
Shalini Kashyap ${ }^{1}$, Sachin Chauhan ${ }^{2}$ \\ ${ }^{1}$ Associate Professor, Department of Pathology, NC Medical College \& Hospital, Israna, Panipat, ${ }^{2}$ Assistant Professor, Department of Pathology, NC Medical \\ College \& Hospital, Israna, Panipat
}

\section{Abstract}

Background: Breast lesions in females are heterogeneous diseases that consist of several distinct entities with remarkably different characteristic features. The present study was conducted to assess histopathological findings of excision biopsies of breast lesions. Subjects and Methods: The present study was conducted on 150 cases of lumpectomy breast specimens received in the department of histopathology. The histopathological diagnosis made after routine processing and hematoxlin and eosin staining. Results: The most common age group of presentation was 30 to 50 years having well defined breast mass lesion. The difference was significant $(\mathrm{P}<0.05)$. Among 150 breast specimens, 145 found to be benign and 05 malignant. In benign, common lesions were fibroadenoma in 64, fibroadenosis in 30, Acute Suppurative inflammatory lesion (Abscess) in 20, fibrocystic disease (FCD) in 22, duct papilloma in 05 and benign phyllodes in 04 cases. In malignant, 04 cases were infiltrative ductal cell carcinoma NOS (Not otherwise specified) and 01 carcinoma in situ. The difference was significant $(\mathrm{P}<0.05)$. Conclusion: Authors found that most common benign breast lesions were fibroadenoma (44.1\%) and fibroadenosis $(20.6 \%)$ followed by acute suppurative inflammatory (Abscess) and FCD.

Keywords: Breast, lump, Histopathology, Fibroadenoma.

Corresponding Author: Dr Sachin Chauhan, Assistant Professor, Department of Pathology, NC Medical College and Hospital, Israna, Panipat.

Email: gauryanheerak@gmail.com

Received: January 2020

Accepted: January 2020

\section{Introduction}

The breast is a modified sweat gland composed of both epithelial and connective tissue elements. Therefore, neoplasms arising from these elements have to be classified separately. Since a long time, various classifications of breast neoplasms has been put forward. ${ }^{[1]}$

Breast lesions are heterogeneous diseases that consist of several distinct entities with remarkably different characteristic features. Most of the breast lesions are well understood and well diagnosed while some of the unusual lesions and malignancies are less appreciated. Majority of the breast lesions initially present with a lump in the breast which is very sensitive for female patients due to which they might not report timely to the doctor for an examination. ${ }^{[2]}$ Benign or malignant lesions do not pose any problem in histopathological diagnosis. But difficulty arises in differentiating between premalignant lesions and carcinoma in situ and minimally invasive carcinoma. There are great differences so far in the prognosis of the lesions concerned. Morphometry and immunohistochemistry (IHC) help to solve this problem. ${ }^{[3]}$

Excision of non-palpable lesions may be performed by various techniques including wide excision, the use of skin markers, radio-opaque dyes and needle localisation. We have found that the use of a guide wire is accurate and reliable. Many biopsies performed on the basis of mammographic changes, however, are due to benign breast disease. As the use of mammography becomes more widespread the number of benign biopsy specimens will increase and histopathologists should be aware of the spectrum of disorders responsible for non-palpable mammographic abnormalities. ${ }^{[4]}$

The WHO statistics in 2008 states that malignant breast lesions comprise 1.38 million cases (10.9\% of total cancer patients). Breast malignancy is the second most common malignancy in women after carcinoma cervix and is diagnosed in 20 in 100,000 women. Fortunately, a majority of the breast lesions are benign. The spectrum of benign breast lesions includes fibroadenoma, benign phylloides tumor, gynecomastia in male, breast abscess, and chronic mastitis etc. ${ }^{[5]}$ The present study was conducted to assess histopathological study of excision biopsies of breast lesions.

\section{Subjects and Methods}

The present study was conducted in the department of general pathology. It consisted of 150 cases of lumpectomy breast specimens. Ethical clearance was obtained prior to the study.

In all cases, age and clinical presentation was recorded. Fine-needle aspiration cytology (FNAC) and 
sonomammography / mammography findings were recorded wherever they were available. The histopathological features were noted, and the tumors were diagnosed based on the WHO classification and graded adopting modified Bloom-Richardson grading system. Results thus obtained were subjected to statistical analysis. $P$ value less than 0.05 was considered significant.

\section{Results}

Table 1: Age wise distribution of cases

\begin{tabular}{|c|c|c|}
\hline Age group (Years) & Number & P value \\
\hline$<30$ & 32 & \multirow[t]{5}{*}{0.01} \\
\hline $30-40$ & 58 & \\
\hline $40-50$ & 40 & \\
\hline $50-60$ & 15 & \\
\hline$>60$ & 05 & \\
\hline
\end{tabular}

Table 2: Histopathological diagnosis of lesions

\begin{tabular}{|l|l|l|}
\hline Lesions & Number & \multirow{2}{*}{ P value } \\
\hline Benign (145) & \multicolumn{2}{|l|}{0.032} \\
\hline Fibroadenoma & 64 & \\
\hline Fibroadenosis & 30 & \\
\hline Acute inflammatory (Abscess) & 20 & \\
\cline { 1 - 2 } Fibrocystic disease & 22 & \\
\cline { 1 - 2 } Duct papilloma & 05 & \multirow{2}{*}{0.011} \\
\cline { 1 - 2 } Benign Phyllodes & 04 & \\
\hline Malignant (05 ) & 01 & \\
\hline Carcinoma in situ & 04 & \\
\hline $\begin{array}{l}\text { Infiltrative duct cell } \\
\text { carcinoma NOS }\end{array}$ & & \\
\hline
\end{tabular}

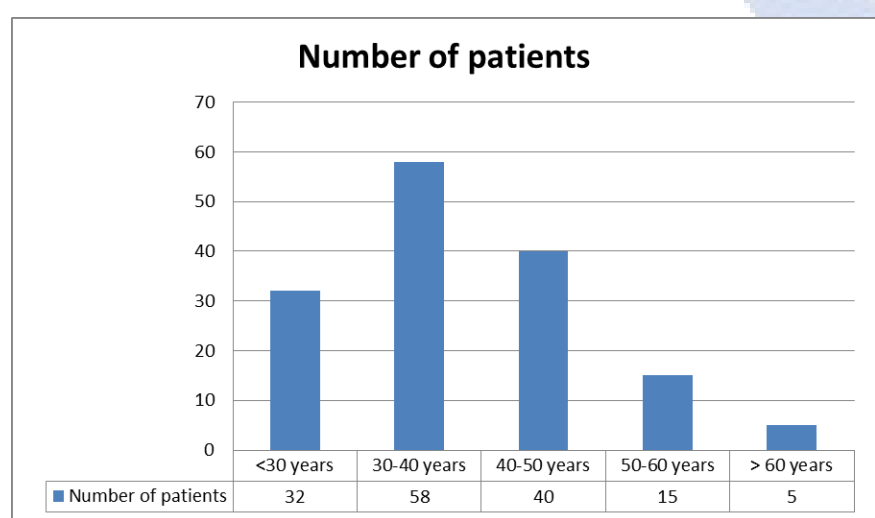

Figure 1: Age wise distribution of cases

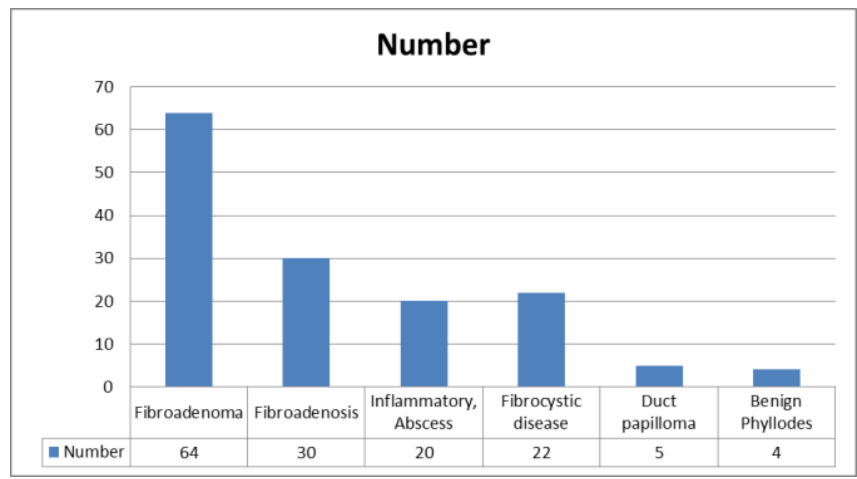

Figure 2a: Benign lesions
[Table 1, Figure 1] shows that age group <30 years had 32, $30-40$ years had 58, 40-50 years had 40, 50-60 years had 15 and $>60$ years had 05 cases. The difference was significant $(\mathrm{P}<0.05)$. Patients presented with palpable lump in the breast, mostly non tender and painless. Sudden increase in size was noted in 10 patients. History of fever and pain was seen in cases of breast abscess and mastitis in them the swelling was soft, tender with overlying skin being erythematous. Puckering of overlying skin was seen in 05 cases.

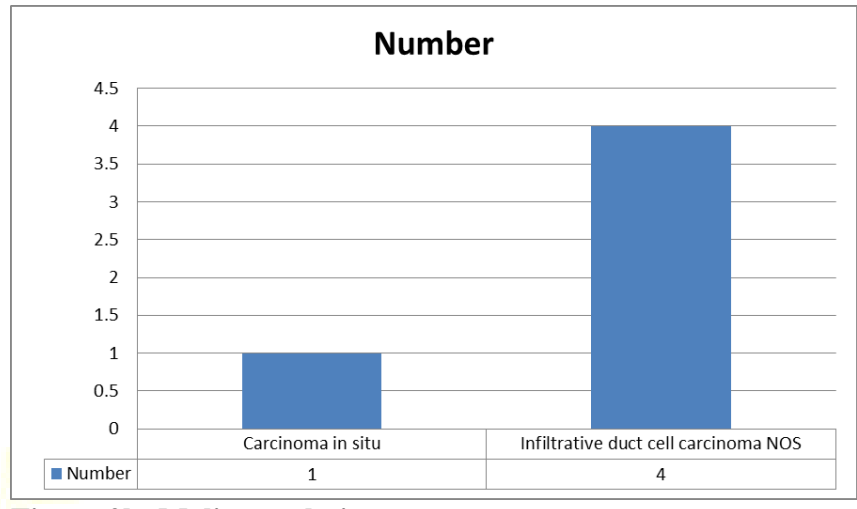

\section{Figure 2b: Malignant lesions}

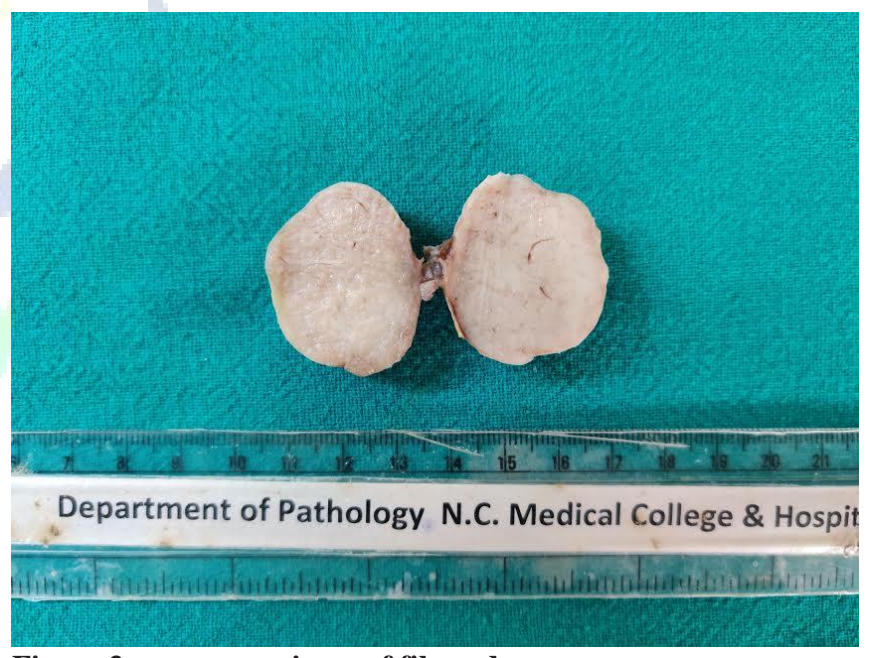

Figure 3a: gross specimen of fibroadenoma.

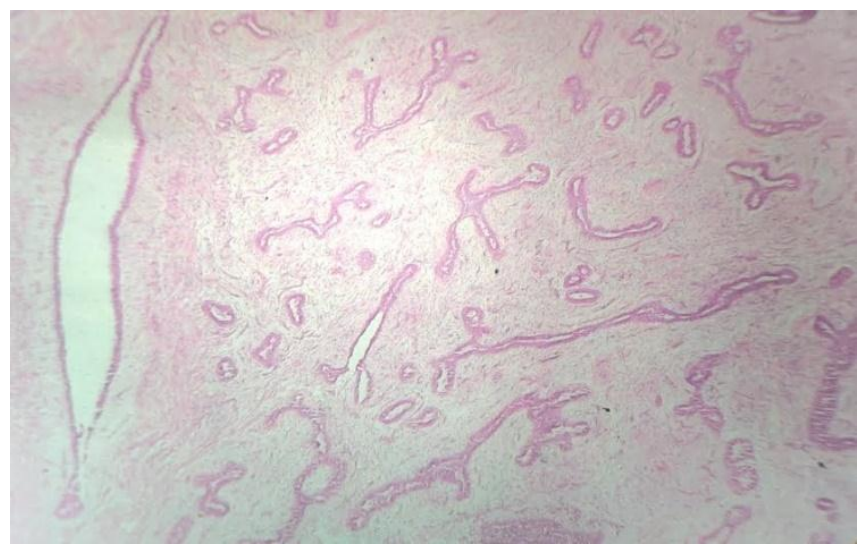

Figure 3b: fibroadenoma showing proliferation of stromal and glandular component 5X, Hematoxylin \& Eosin. 
[Table 2, Figure 2a \& 2b] shows that among 150 breast specimens, 145 found to be benign and 05 malignant. In benign, common lesions were fibroadenoma in (fibroadenosis in 30, acute suppurative inflammatory (Abscess) in 20, fibrocystic disease in 22, duct papilloma in 05 and benign phyllodes in 04 cases [Figure 3a, 3b]. In malignant infiltrative duct cell carcinoma in 04 cases and carcinoma in situ in 01 cases [Figure 4a,4b]. The difference was significant $(\mathrm{P}<0.05)$.

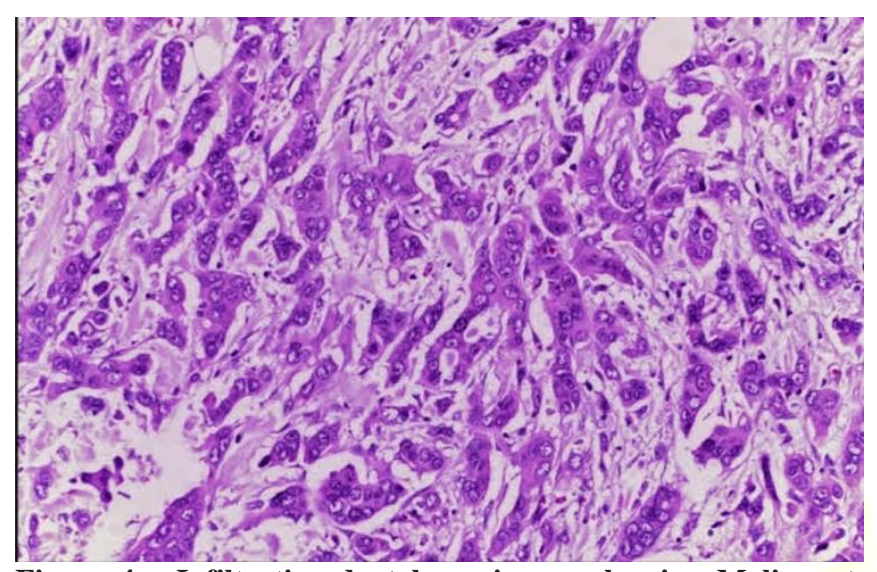

Figure 4a: Infiltrative ductal carcinoma showing Malignant cells infiltrating fibromuscular stroma. 40X, Hematoxylin \& Eosin.

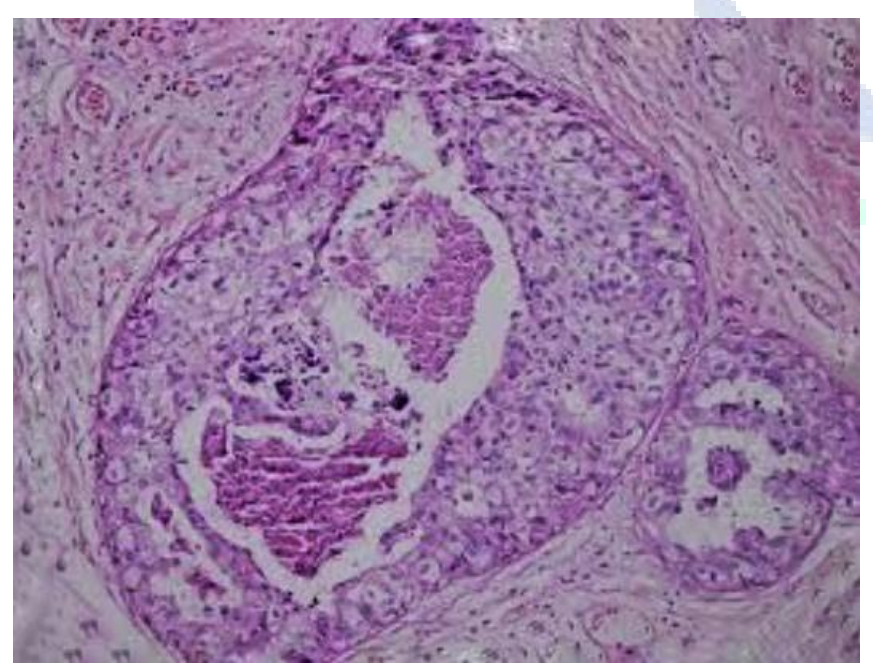

Figure 4b: Carcinoma in situ (comedo) mammary duct showing proliferation of highly atypical glandular cells with no infiltration of basement membrane and adjoining stroma. 40X ; Hematoxylin \& Eosin.

\section{Discussion}

The incidence of cancer has increased from 12.7 million in 2008 to 14.1 million in 2012, and this development is likely to continue in the future. The most frequently identified cancers were lung (1.82 million) and breast (1.67 million). Epidemiological studies have indicated an increased breast cancer incidence among women actively contributing to social and professional life. This necessitates the need for conducting multidirectional studies in order to find risk factors associated with the etiology of breast cancer. ${ }^{[5]}$ Previous studies have showed that $20-30 \%$ of newly diagnosed breast cancer cases may be caused by various risk factors actively initiating or modifying the process of neoplastic transformation. The most common risk factors are age over 40 , history of mammary gland diseases, history of cancer in first-degree relatives, early menarche and late childbearing (after 35 years of age), woman's age and others. Continuous research in different dimensions can help in reducing the overall breast cancer burden, and detects cancer in the early stage and enable the possibility of treatment. ${ }^{[7]}$ The present study was conducted to assess histopathological study of excision biopsies of breast lesions.

In present study, most common age group of presentation was between 30 to 50 years. We found that among 150 breast specimens, 145 were found to be benign and 05 malignant. In benign, common lesions were fibroadenoma (44.1\%) and fibroadenosis (20.6\%) followed by Acute suppurative inflammatory (abscess) and FCD. In malignant, infiltrative ductal cell carcinoma NOS was common.

Yogalakshmi et al, ${ }^{[8]}$ evaluated the frequency, age, gender, and histopathological features of breast carcinoma in a tertiary care hospital. In all cases, the histopathological features were noted. Of the 120 specimens received, 116 specimens belonged to female patients (97\%). The peak age of the occurrence of breast masses was in the 3rd decade (32\% occurrence). Both malignant and non-malignant lesions were present in the specimens. Among the 98 benign lesions, 45 cases were of fibroadenoma (46\%), 23 cases were of fibroadenosis (23\%). Among the 22 malignant lesions, 17 cases were of infiltrative duct cell carcinoma $(77 \%)$.

Mudholkar et al, ${ }^{[9]}$ found that out of total 9086 biopsies, breast biopsies were 366 (4\%) during this 5 year study. Total 252 breast neoplasms were studied, where, the incidence of benign neoplasms was 50.4\% (127 cases) \& for malignant neoplasms was $49.6 \%$ (125 cases). Among all types of specimen received, excision biopsy was most common (48\%). Upper outer quadrant was most commonly involved region for breast neoplasms. Fibroadenoma, benign phyllodes neoplasm, tubular adenoma, central papilloma, peripheral papilloma, lipoma and neurofibroma were seen among benign neoplasms. While invasive ductal carcinoma not otherwise specified, mixed carcinoma, metaplastic carcinoma, mucinous carcinoma, malignant phyllodes neoplasm, invasive lobular carcinoma, invasive papillary carcinoma, medullary carcinoma, intracystic papillary carcinoma, malignant peripheral nerve sheath neoplasm and collision neoplasm were studied among malignant neoplasms. The most common benign neoplasm was fibroadenoma (87\%) and invasive ductal carcinoma not otherwise specified NOS (88\%) was malignant neoplasm.

Rikabi et al, ${ }^{[10]}$ included a total of 275 trucut biopsies were performed during the study period. Histopathology showed $92(33.5 \%)$ malignant lesions, 177 (64.3\%) benign lesions and $6(2.2 \%)$ suboptimal or suspicious lesions. Repeat trucut biopsies were done in $29(16.4 \%)$ of the benign cases, $12(13 \%)$ of the malignant cases, and for 6 inconclusive 
specimens which showed 4 of the 29 benign cases to be malignant lesions, and 5 of the 6 inconclusive cases were also malignant lesions. All 12 malignant cases that had repeat trucut biopsy had a confirmed diagnosis of malignancy. Trucut biospy had a sensitivity of $95.1 \%$, specificity of $100 \%$, positive predictive value of $100 \%$, negative predictive value of $97.2 \%$, and an overall diagnostic accuracy of $98.2 \%$.

\section{Conclusion}

Authors found that most common benign breast lesions were fibroadenoma and fibroadenosis with infiltrative ductal carcinoma being the most common malignancy.

\section{References}

1. Gail MH, Brinton LA, Byar DP, Corle DK, Green SB, Schairer C, et al. Projecting individualized probabilities of developing breast cancer for white females who are being examined annually. J Natl Cancer Inst
1989;81:1879-86.

2. Siddiqui MS, Kayani N, Gill MS, Pervez S, Muzaffar S, Aziz SA, et al. Breast diseases: A histopathological analysis of 3279 cases at a tertiary care center in Pakistan. J Pak Med Assoc 2003;53:94-7.

3. Mansoor I. Profile of female breast lesions in Saudi Arabia. J Pak Med Assoc 2001;51:243-7.

4. Hislop TG, Elwood JM. Risk factors for benign breast disease: A 30year cohort study. Can Med Assoc J 1981;124:283-91.

5. Parazzini F, La Vecchia C, Franceschi S, Decarli A, Gallus G, Regallo $\mathrm{M}$, et al. Risk factors for pathologically confirmed benign breast disease. Am J Epidemiol 1984;120:115-22.

6. Ellis $\mathrm{H}, \mathrm{Cox}$ PJ. Breast problems in 1,000 consecutive referrals to surgical out-patients. Postgrad Med J 1984;60:653-6.

7. Malik R, Bharadwaj VK. Breast lesions in young females a 20-year study for significance of early recognition. Indian J Pathol Microbiol $2003 ; 46: 559-62$.

8. Yogalakshmi S, Kavitha M. A Study of Histopathological Spectrum of Breast Lesions. Int J Sci Stud 2019;7(1):1-5.

9. Mudholkar VG, Kawade SB, Mashal SN. Histopathological study of neoplastic lesions of breast. Indian Medical Gazette. 2012;145(9):35364 .

10. Rikabi A, Hussain S. Diagnostic usefulness of tru-cut biopsy in the diagnosis of breast lesions. Oman medical journal. 2013 Mar;28(2):125.

Copyright: (C) the author(s), 2020. It is an open-access article distributed under the terms of the Creative Commons Attribution License (CC BY 4.0), which permits authors to retain ownership of the copyright for their content, and allow anyone to download, reuse, reprint, modify, distribute and/or copy the content as long as the original authors and source are cited.

How to cite this article: Kashyap S, Chauhan S. Study of Histopathological Patterns in Breast Lumps. Asian J. Med. Res. 2020;9(1):PT12PT15.

DOI: dx.doi.org/10.47009/ajmr.2020.9.1.PT4

Source of Support: Nil, Conflict of Interest: None declared. 